\title{
Coronary Calcium Score in the Evaluation of Diabetic Patients without Coronary Arteries Disease Symptoms
}

\author{
Alexander Valdés Martín* \\ Institute of Cardiology and Cardiovascular Surgery, Cuba
}

Submission: February 11, 2017; Published: March 23, 2017

*Corresponding author: Alexander Valdés Martín, Institute of Cardiology and Cardiovascular Surgery, Havana, Cuba, Email: avaldes@infomed.sld.cu

\begin{abstract}
Diabetic patients are more likely to have an acute coronary syndrome or even sudden silent death. Among the diabetic population there is the paradox of an early onset of coronary disease and a late diagnosis due to the absence of a striking clinic. Angina in the diabetic patient usually has an atypical presentation. The technique described by Agatston to quantify coronary calcium consists in measuring the total area of calcified coronary plaque in pixels, cut by cut, assigning a score. Coronary artery calcification has been shown to be an excellent measure of atherosclerotic load in epicardial vessels. The calcium in coronary arteries is related to cardiac events in the general population and its quantification is consistently higher in patients with clinic coronary disease. The presence of vascular calcification may provide an additional reason for both the physician and the patient to adopt more intensive prevention strategies on risk factors.
\end{abstract}

Keywords: Coronary calcium score; Diabetes mellitus; Atherosclerosis; Multiple detector computed tomography

Abbreviations: CAS: Coronary Artery Calcification; CCS: Coronary Calcium Score

\section{Introduction}

Diabetic patients are more likely to have an acute coronary syndrome or even sudden silent death. It is postulated that the basis of silent ischemia is an autonomic neuropathy with involvement of the cardiac sensory innervations [1]. Among the diabetic population there is the paradox of an early onset of coronary disease and a late diagnosis due to the absence of a striking clinic. Angina in the diabetic patient usually has an atypical presentation. It occurs with a frequency that varies between $20 \%$ and $44 \%$ according to the studies. The pain can be located at the mandible angle, neck or epigastrium, and it also can be associated with vomiting [2]. The prevalence of acute myocardial infarction in the diabetic population is increased in all ages. In addition, the existence of diabetes annuls the epidemiological benefit of the female sex for ischemic heart disease. The Framingham study showed that the prevalence of age-adjusted acute myocardial infarction in adults from 35 to 65 years old was twice as high for diabetic men as for non-diabetic men and triple for diabetic women than for women free of this disease. These data are similar in studies carried out in other populations [3]. The survival after an acute myocardial infarction is also significantly reduced in the diabetic population, basically due to the higher frequency of complications such as early stage mortality, cardiogenic shock, myocardial rupture, acute arrhythmias and heart failure [4].

\section{Discussion}

Intimal calcification of the coronary arteries is part of the evolutionary process of atherosclerosis at that level. It occurs almost exclusively in the arterial segments affected by this process, usually in small amounts during the initial stages of atherosclerotic lesions, and more frequently in lesions and advanced ages $[5,6]$. Although there is a positive correlation between site and quantity of coronary calcium and percent coronary stenosis in the same anatomical site, the relationship is nonlinear and has large confidence limits [7].

The coronary arteries calcification is almost exclusively in the context of atherosclerosis, except in patients with renal failure where there may be calcification not related to atherosclerosis. The technique described by Agatston [8] to quantify coronary calcium consists in measuring the total area of calcified coronary plaque in pixels, cut by cut, assigning a score. The Agatston's calcium score is obtained as a result of the multiplication of the area of the calcified lesion by a factor dependent on the peak 
signal intensity of the lesion. Coronary artery calcification (CAS) has been shown to be an excellent measure of atherosclerotic load in epicardial vessels. The calcium in coronary arteries is related to cardiac events in the general population and its quantification is consistently higher in patients with clinic coronary disease $[9,10]$.

Coronary calcium score (CCS) determined through multiple detector computed tomography is an excellent noninvasive method for detecting coronary atherosclerosis in subclinical stages. This technique establishes the presence of calcium in the wall of coronaries arteries predicting the risk of coronary events in the long term. Subjects with no CAC or low CCS are less likely to present cardiovascular events than those with elevated scores [11]. At present, the use of CCS focuses on two clinical areas of interest: 1) Risk assessment in asymptomatic patients, with the purpose of modifying and potentially improving their lifestyle. 2) Its use in symptomatic patients as a means to select which of them may require hospitalization, additional diagnosis or invasive procedures.

As a general line and based on a consensus, patients may be divided into groups according to the extension of the disease: Absence of calcification; minimal calcification (1-10); mild (11100); moderate (101-400); severe (401-1000); and extensive (more than 1000). Patients may also be divided according to percentile of age, gender, and ethnicity [9]. A CCS greater than 1000 is associated with a $25 \%$ annual risk of having a cardiovascular event (and therefore translates a need for aggressive treatment measures in these patients). Budoff et al. [12] point out that the best way to assess the test result is to use the absolute value of coronary calcium, using values of 100 and 400 to differentiate between patients at low and very high risk. The PREDICT study [13], which included 589 patients with type 2 Diabetes Mellitus without a history of cardiovascular disease, showed a CCS of less than 10AU in $23.4 \%$ and a CCS greater than $400 \mathrm{AU}$ in $25.5 \%$. Anand et al. [14] reported a higher prevalence in asymptomatic diabetics, since $46.3 \%$ had a CCS greater than $10 \mathrm{AU}$. In a recent comparative study lead in Cuba by Peix et al. [15], the CCS in diabetic patients was $74.1 \pm 168$.8AU vs $5.2 \pm 14.6 \mathrm{AU}$ in controls, $\mathrm{p}<0.01$. Furthermore they found that the $13.6 \%$ diabetic patients had a CCS greater than 100AU. On the other hand, in the presence of a score of zero, there is a small probability of disease in patients with low to intermediate risk, even in those showing symptoms [16]. Moreover; it denotes that the disease does not show great extent, which is a good prognostic indicator. The absence of calcium in the coronary determines an annual risk close to $0.1 \%$ [17]. The presence of vascular calcification may provide an additional reason for both the physician and the patient to adopt more intensive prevention strategies on risk factors such as smoking, hypertension, lipids and glycemic control.

\section{Conclusion}

Literature review shows that Coronary calcium score play an important role in the diagnostic evaluation of atherosclerotic heart disease, especially in the diabetic patient. The possibility of removing extensive coronary disease by means of a calcium score zero, or indicating the presence of an extensive disease when it is severely increased, justifies the use of this method in the initial or joint evaluation, in asymptomatic patients with suspected coronary artery disease and in cardiovascular risk stratification.

\section{References}

1. Otero F, Mazón-Ramos P, Grigorian-Shamagian L, Nores-Lorenzo A, Zugaza-Gurruchaga L, et al. (2010) Influence of diabetes in the clinic characteristic and prognostic of patients with chronic ischemic cardiopathy. CIBAR Study. Rev Esp Cardiol 63(11): 1371-1376.

2. Señor BV, Puertas NA, Pinilla SMA, Lacasa RC, Pérez PP, et al. (2007) Endotelial dysfunction, coronary disease and diabetes mellitus. Endocrinol Nutr 54: 467-472.

3. Buyken AE, von Eckardstein A, Schulte H, Cullen P, Assmann G (2007) Type 2 diabetes mellitus and risk of coronary heart disease: results of the 10-year follow-up of the PROCAM study. Eur J Cardiovasc Prev Rehabil 14(2): 230-236.

4. González-Clemente JM, Palma S, Arroyo J, Vilardell C, Caixás A, et al. (2007) Is diabetes mellitus a coronary heart disease equivalent? Results of a meta-analysis of prospective studies. Rev Esp Cardiol 60(11): 1167-1176.

5. Llerena R, Peix A, Valiente J (2011) Noninvasive image technique in the evaluation and prevention of the coronary disease. Rev Cub Cardiol Cir Cardiovasc 17: 47-57.

6. Motoyama S, Sarai M, Harigaya H, Anno H, Inoue K, et al. (2009) Computed tomographic angiography characteristics of atherosclerotic plaques subsequently resulting in acute coronary syndrome. J Am Coll Cardiol 54(1): 49-57.

7. Madder RD, Chinnaiyan KM, Marandici AM, Goldstein JA (2011) Features of disrupted plaques by coronary computed tomographic angiography correlates with invasively proven complex lesions. Circ Cardiovasc Imaging 4(2): 105-113.

8. Agatston AS, Janowitz WR, Hildner FJ, Zusmer NR, Viamonte M, et al. (1990) Quantification of coronary artery calcium using ultrafast computed tomography. J Am Coll Cardiol 15(4): 827-832.

9. Detrano R, Guerci AD, Carr JJ, Bild DE, Burke G, et al. (2008) Coronary calcium as a predictor of coronary events in four racial or ethnic groups. N Engl J Med 358(13): 1336-1345.

10. Polonsky TS, McClelland RL, Jorgensen NW, Bild DE, Burke GL, et al. (2010) Coronary artery calcium score and risk classification for coronary heart disease prediction. JAMA 303(16): 1610-1616.

11. Coylewright M, Rice K, Budoff MJ, Blumenthal RS, Greenland P, et al. (2011) Differentiation of severe coronary artery calcification in the multiethnic study of atherosclerosis. Atherosclerosis 219(2): 616-622.

12. Budoff MJ, Nasir K, McClelland RL, Detrano R, Wong N, et al. (2009) Coronary calcium predicts events better with absolute calcium scores than age-sex-race/ethnicity percentiles: MESA (Multi-Ethnic Study of Atherosclerosis). J Am Coll Cardiol 53(4): 345-352.

13. Elkeles RS, Feher MD, Flather MD, Godsland IF, Nugara F, et al. (2004) The association of coronary calcium score and conventional 
cardiovascular risk factors in type 2 diabetic subjects asymptomatic for coronary heart disease (the PREDICT study). Diabet Med 21(10): $1129-1134$

14. Anand DV, Lahiri A, Lim E, Hopkins D, Corder R (2006) The relationship between plasma osteoprotegerin levels and coronary artery calcification in uncomplicated type 2 diabetic subjects. J Am Coll Cardiol 47(9): 1850-1857.

15. Peix A, Cabrera LO, Heres F, Rodríguez L, Valdés A, et al. (2011) Interrelationship between myocardial perfusion imaging, coronary calcium score, and endothelial function in asymptomatic diabetics and controls. J Nucl Cardiol 18(3): 398-406.

16. Yeboah J, McClelland RL, Polonsky TS, Burke GL, Sibley CT, et al. (2012) Comparison of novel risk markers for improvement in cardiovascular risk assessment in intermediate-risk individuals. JAMA 308(8): 788795 .

17. Shaw LJ, Giambrone AE, Blaha MJ, Knapper JT, Berman DS, et al. (2015) Long-term prognosis after coronary artery calcification testing in asymptomatic patients: a cohort study. Ann Intern Med 163(1): 14-21.

\section{Your next submission with Juniper Publishers will reach you the below assets}

- Quality Editorial service

- Swift Peer Review

- Reprints availability

- E-prints Service

- Manuscript Podcast for convenient understanding

- Global attainment for your research

- Manuscript accessibility in different formats

( Pdf, E-pub, Full Text, Audio)

- Unceasing customer service

Track the below URL for one-step submission https://juniperpublishers.com/online-submission.php 